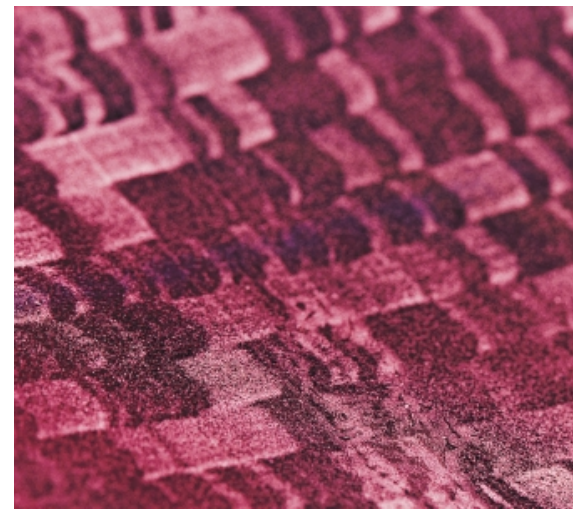

have obvious applications in fighting diseases, by recognizing damaged cells or tissue and either reporting the problem or, even better, effecting the release of reparative molecules.

Another promising direction is the molecular self-assembly of DNA to build complex molecular structures, which could have an impact on other fields, such as nanotechnology. Eric Winfree, from the California Institute of Technology, USA, has devoted considerable amounts of time to this topic, and has developed a method for building molecular 'tiles' - minute blocks of DNA. By programming the edges of these tiles, he has been able to force DNA to come together in tiny molecular patterns. He has so far only been able to build simple structures, however, and, he said, "we need to get to the point where we can construct complicated patterns."

Y et, as Amos pointed out, "this is all blue sky at the moment." All of this research is still in the proof-of-principle stage, and any practical applications are at least five to ten years away. Clearly, DNA computing will not become a rival for today's silicon-based machines and "it will not affect the way you or I live," said Weiss. However, the real excitement in the field lies in bringing together biologists, chemists, computer scientists and mathematicians to understand and simulate fundamental biological processes and algorithms taking place within cells. "We shouldn't be looking for competition with traditional machines, we should be looking outside the box for a niche for other applications." said Amos. However, he added, "If I'm honest, biocomputing has yet to establish this niche."

\section{Jack Parker}

DOI: 10.1038/embor719

\title{
Back to the roots
}

New knowledge and technologies are already improving plant breeding. But will it be enough to provide sufficient food for the world's growing population?

$\mathrm{P}$ lant science and agriculture are facing a conundrum. A growing human population, coupled with global warming and decreasing water supplies, are putting immense pressure on those involved to meet these challenges without further contributing to the destruction of the environment. But basic and applied research on crop improvement, particularly the genetic modification of plants, has come under heavy criticism from environmental groups, who fear that genetically modified (GM) crops might become a threat to the environment and consumer health. These groups have largely succeeded in rallying public support for their cause and, in reaction to their heavy lobbying, the European Union, and some developing countries, now demand strict safety tests for every GM crop. This creates additional costs for plant breeders and companies, and further postpones the introduction of new improved lines. Using the information and technologies from plant research to improve the breeding process without resorting to GM could overcome this bottleneck.

Indeed, the challenges for agriculture in the twenty first century are probably even higher than the pre-green revolution days of the 1940s. According to estimates from the United Nations Population Fund, the world population may well hit the 10 billion mark by 2050 , and global grain production needs to double to feed them. The majority of these people, in both the developed and the developing world, will live in ever-larger cities, which puts even more stress on agriculture to produce, store and distribute the food needed for this urbanized population. And it is not just a matter of producing enough rice, maize or wheat. Already, millions suffer from malnutrition because their diet relies on one or two major crops that do not provide them with all the essential micronutrients they need.

Simply turning more virgin areas into arable land is certainly not the solution. About half of the usable global land is already dedicated to pastoral or intensive agriculture, and the remaining ecosystems are rapidly disappearing as farmers move into formerly unpopulated areas, creating even more problems. According to the United Nations Convention to Combat

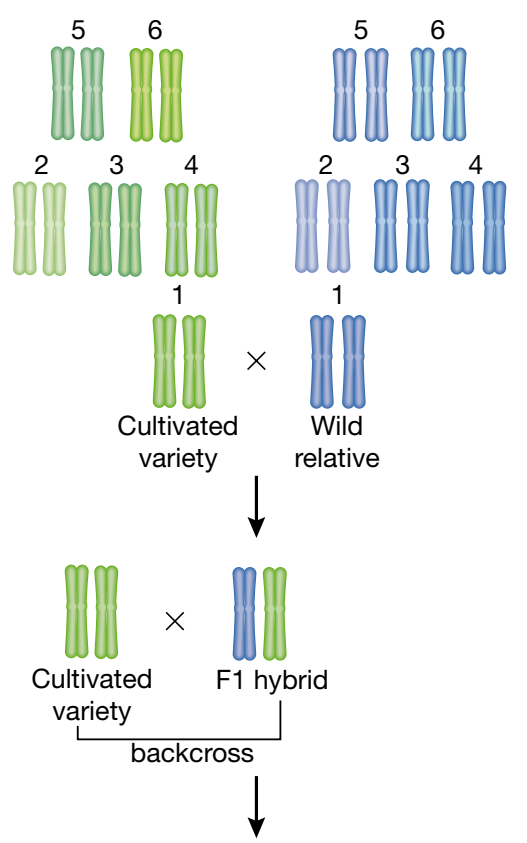

Backcrossing and marker-assisted selection

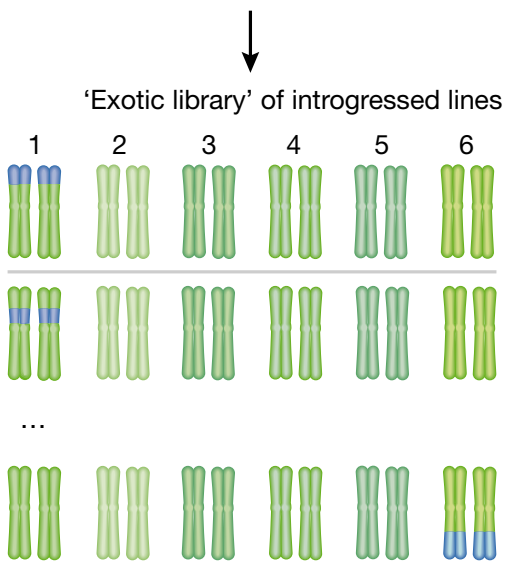

Fig.1. Generation of an exotic library of high-yield crop and a wild relative. Zamir D. 2001, Nature Reviews Genetics 2, 983-9. 


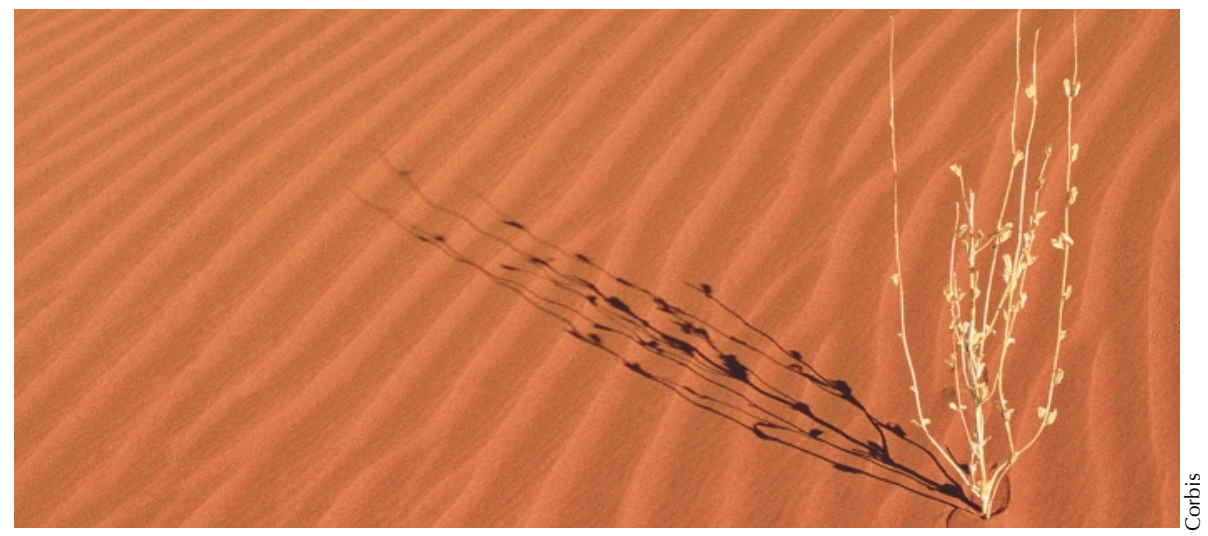

Desertification, overuse, deforestation and poor irrigation practices have already degraded most of the world's drylands, and as much as 3.6 billion hectares - more than the land mass of Europe - are now deserts where only the hardiest plants survive.

The industrialized agricultural practices used in parts of the developed world are also at their limit of production. Farmers in California's Central Valley, who supply half of the USA's fruit and vegetables, are pumping water from underground aquifers faster than nature can replace it, and in the Southern Great Plains, cotton and grain farmers are steadily depleting the Ogallala, one of the world's largest aquifers. Water is now the main bottleneck for agriculture, and access to it has become a political issue in many parts of the world; last year, Lebanon caused a diplomatic crisis with Israel when it built new pumps near its southern border to draw water from the Jordan river that Israel claims for its farmers. Furthermore, there are growing concerns about the environmental impact of fertilisers, pesticides and herbicides, as well as the increasing mechanization of agriculture - all contributors to the green revolution. "The mechanical and engineering solutions are unlikely to make the same contributions as genetic solutions," said Pat Heslop-Harrison from Leicester University's Biology Department. "Improvement will come from improved seeds that we plant scientists will deliver to the farmers."

$\mathrm{B}$ ut these improved seeds are fraught with problems of their own. Public acceptance of GM crops in many countries remains elusive, and strict safety guidelines are postponing or preventing the introduction of new pesticide-, salt-, or drought-resistant plants. Plant scientists have therefore started exploring other ways to improve food crops, particularly using emerging technologies to improve breeding techniques. The sequencing of several plant genomes, most notably the Arabidopsis and the rice genomes, has provided them with a wealth of information to improve the efficiency of the classical breeding process. "I think molecular techniques could improve classical breeding in many ways," said Heslop-Harrison. "Current applications of genetic and molecular markers are potentially speeding up the breeding process by 2 to 3 years." Breeders already use markerassisted selection to measure and quantify genetic combinations and to follow desirable traits through the multiple generations of crosses and backcrosses needed to develop a new plant line.

\section{About half of the usable global land is already dedicated to pastoral or intensive agriculture}

However, this approach is only beginning to bear fruit, and even though information from the various plant genome projects is pouring in, breeders face other limitations. All major crops planted today are based on the selective breeding of a very small number of wild plants that farmers domesticated 10,000 years ago. Therefore, today's crops contain only a fraction of the genetic variation that is present in their wild relatives. Dani Zamir from Jerusalem University documented this problem at the European Plant Science Organisation (EPSO) meeting last October in Brunnen, Switzerland, highlighting Californian breeders, who have not succeeded in further increasing the amount of soluble compounds in the fruits. "This is, we believe, because they exhausted their genetic diversity," Zamir said.
One way to overcome these genetic limitations is to go back into the wild and cross domesticated crops with their wild relatives in order to gain access to useful traits, such as pest- or drought-resistance. But it is not that easy. "It takes many years of backcrossing to breed out 'unpleasant' genes, and in many cases the wild relatives do not contain the genes you require to improve the crop," said Christopher Leaver of Oxford University's Department of Plant Sciences. There are also other problems, such as cross incompability, F1 hybrid sterility and reduced chromosomal recombination rates.

Zamir has developed a new approach that he calls "exotic libraries", to overcome these limitations. Such an exotic library consists of a large number of lines, each of which carries a small, well-defined chromosomal segment from the wild plant in the genome of the domesticated crop, and the whole genome of the wild relative is represented in a complete exotic library (Fig. 1). Zamir is interested in improving tomatoes, particularly in developing drought-resistant plants adapted to the dry conditions of the Middle East. He collected hardy, wild Lycopersicon pennellii tomato plants in the deserts of Western Peru, crossed them with a M82 high-yield tomato line used by Israeli farmers, and backcrossed for 8 generations, using markerassisted selection to develop a library of 50 introgression lines. Zamir's group, in cooperation with the Palestinian authorities, then screened this library for drought-resistance and yield improvement. They eventually

\section{PRODUCTION OF MAJOR FOOD CROPS IN 2001}

(FAO Statistical Database http://apps.fao.org).

$\begin{array}{lc}\text { Crop } & \begin{array}{c}\text { Production in 2001 } \\ \text { in million tons }\end{array} \\ \text { Rice } & 593 \\ \text { Wheat } & 579 \\ \text { Maize } & 605 \\ \text { Potatoes } & 308 \\ \text { Cassava } & 179 \\ \text { Sugar Cane } & 1254 \\ \text { Sugar Beets } & 234 \\ \text { Soybeans } & 177 \\ \text { Barley } & 139 \\ \text { Tomatoes } & 100 \\ \text { Bananas } & 98 \\ \text { Grapes } & 62 \\ \text { Oranges } & 61 \\ \text { Apples } & 60 \\ \text { Watermelons } & 77 \\ \text { Cabbages } & 55 \\ \text { Onions } & 47 \\ \text { Groundnuts } & 35\end{array}$




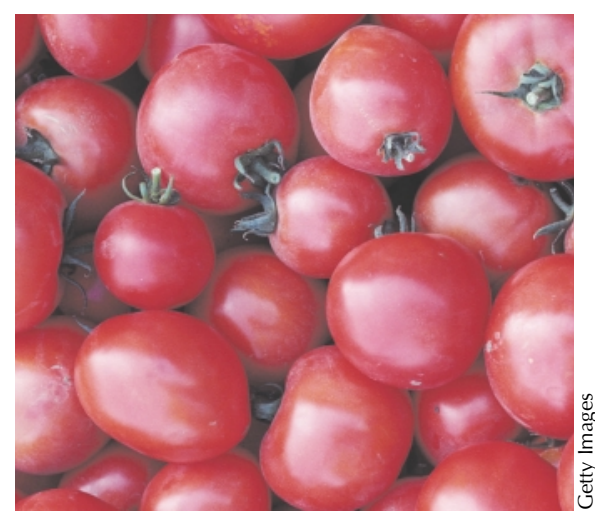

identified three promising lines and, by crossing these again, produced a droughtresistant tomato that does not rely on irrigation, while producing a whopping 130\% higher yield than the original M82 line.

However, the usefulness of such exotic libraries extends much further, thinks Zamir. Once generated, they are a representation of wild plant genes that breeders can easily and quickly screen for a wide variety of useful traits, considerably shortening the time to develop new crops. Exotic libraries of domesticated crops crossed with various wild germlines would thus overcome both the narrowed genetic variability of today's high-yield crops, and provide an immensely valuable resource for breeders to improve upon, he predicts. But it comes at a price. "Establishing such a resource will require investing a considerable amount of time and money into developing the many introgressed lines and into an integrated bioinformatics framework that can collate and make available the phenotyping and mapping information from these lines," Zamir commented on his work in an article in Nature Reviews Genetics (D. Zamir, Nature Reviews Genetics, 2, 983-989; 2001).

W hile wild relatives and traditional seeds, known as landraces, clearly provide an abundance of potentially useful traits, it would also be helpful to take a closer look at domesticated crops - albeit indirectly. As Maarten Koornneef from Wageningen University's Department of Agrotechnology and Food Sciences in The Netherlands explained at the EPSO meeting, model plants such as Arabidopsis are harbouring a wealth of information that could be used to improve the nutritional quality of crops, namely their levels of vitamins, sugars, minerals and antioxidant chemicals, such as phenolic compounds or flavoids. By identifying the genes involved in these metabolic pathways in Arabidopsis, and then identifying their orthologues in crop plants, breeders could use the latter as highly specific markers to develop new lines. His own group is currently exploring the metabolism of various oligosaccharides in seeds, and another possible application would be to increase their amount of micronutrients for people who rely on mainly cereal-based diets that are low in essential vitamins and iron.

Elsewhere, Jonathan Gershenzon at the Max Planck Institute for Chemical Ecology in Jena, Germany, and Richard Mithen at the University of Nottingham, UK, have already cloned the Arabidopsis genes involved in synthesizing glucosinolates, compounds with anti-carcinogenic properties that also provide insect resistance and increase flavour. They also identified the orthologues in Brassica, which could be used as markers to breed plants that produce a higher amount of glucosinolates. Researchers in the USA and the UK are also deciphering the pathways involved in synthesizing various vitamins, with the aim of using this knowledge to improve crop plants.

\section{Exotic libraries could overcome the problem of narrowed genetic variability of today's high-yield crops}

However, there is much more out there to explore than just plants and their genomes, as Dieter Haas from the University of Lausanne in Switzerland pointed out. A microbiologist, he is interested in the bacteria that live in peaceful and mutually beneficial symbiosis with their plant hosts. These "biocontrolling agents" as he called them, produce and release a whole pharmacy of antibiotic compounds, phytohormones and polysaccharides which protect the plant from the daily assault of viruses, bacteria and fungi - "all of these come together and cause the biocontrol," explained Haas. But, the economic focus, he pointed out, has so far been on biopesticides, such as Bacillus thuringiensis. Research on symbiotic biocontrolling bacteria might therefore provide new avenues for researchers to improve stress resistance without necessarily genetically modifying plants. However, fiddling with symbiotic bacteria may eventually hit the same snags as GM plants, as the potential long-term consequences for the environment remain unclear.
C learly, the accumulating information on plant genomes, new breeding techniques and knowledge of microbial symbionts will be beneficial. But it will take time. "I am convinced that having the model genomes will absolutely improve plant improvement," said HeslopHarrison. "But we still need to learn how we can use this information from those model species. ... It won't be overnight." And time is running out, given the pressures on agriculture to produce more and better food. Furthermore, it might not even be enough. "There are a number of desirable genes underlying important traits that do not exist in the main crop lines," said Leaver, and these therefore have to be identified in and isolated from other sources: "You have to use appropriate technology for the challenge at hand." And that inevitably includes genetic modification, he thinks, because introducing traits that are not present in the existing crops or their wild relatives will ultimately require GM technology.

In this regard, the current political situation in Europe and some developing countries further postpones the development of new, improved plant lines. Companies implementing the fruits of plant research are already leaving the UK and relocating to the USA, Leaver said, and those in academia are also suffering from the political storms. "It is a worry that if we take 5 or 10 years to develop these tests, then there might be a lot of people in the developing world who won't have access to improved foods," feared Heslop-Harrison. Furthermore, the demand for strict safety controls in Europe is also seen as a new form of imperialism by the First World in not giving access to technologies and information that breeders and scientists in the developing world urgently need. "We are denying people the possibility to evaluate and deploy the technology if it is appropriate to their needs," said Leaver, describing this attitude as a "type of latterday neo-colonialism."

The public attitude might change, however, thinks Heslop-Harrison. "Ultimately, if the safety arguments are working out correctly and if the tests are in place, then yes, there will be acceptance," he said. "It is important to point out that the benefits are to all people not just a small group of multinationals as it is often presented."

\section{Holger Breithaupt}

DOI: $10.1038 / \mathrm{embor} 720$ 